\title{
Hepatitis B Surface Antigen (Obsag) in Pregnant Women Attending Antenatal Clinic at The General Hospital, Amaku, Awka, Anambra State, Nigeria
}

\author{
Effiong Edet Bassey* and Ebere I Okoye \\ Department of Applied Microbiology and Brewing, Nnamdi Azikiwe University, Awka, Nigeria
}

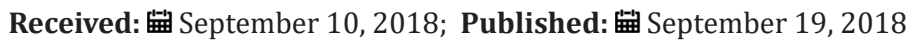

*Corresponding author: Effiong Edet Bassey, Department of Applied Microbiology and Brewing, Nnamdi Azikiwe University, Awka, Nigeria

\begin{abstract}
This study was carried out to determine the prevalence of HBsAg among pregnant women attending antenatal clinic at General Hospital in Agba, Ekwulobia, Anambra State. Two hundred pregnant women who consented voluntarily after thorough explanation of the purpose of the study were recruited for this study. The samples were tested for the presence of antibodies using rapid Dia Spot HBsAg rapid test strip developed by Dia Spot Diagnostics, USA and ClinotechHBsAg (Clinotech diagnostics, Richmond, Canada). Analysis of the result showed that 23(11.5\%) of the pregnant women had HBsAg. Statistical analysis, however, showed no significant difference between the prevalence and the age of patients, parity, trimester and type of family. The frequency of HBY carriers did not vary significantly with the Use of condoms and contraceptives. However, there was a significant frequency variation in the distribution of HBsAg between those that have previous history of transfusion, operation, circumcision and those who never had history of operation, transfusion or circumcision Therefore, the need to institute public health measures to reduce disease burden and transmission, including routine screening of all pregnant mothers for HBV infection and early passive-active immunization of babies born to HBsAg-positive mothers are advocated.
\end{abstract}

\section{Introduction}

Hepatitis, B virus is a hepadnavirus-hepa from hepatotropic (attracted to the liver) and DNA because it is a DNA virus [1]. The viruses replicate through an RNA intermediate form by reverse transcription, which in practice relates to retroviruses (Locarnini $S$ 2004). It is 50 to 100 times more infectious than HIV. It is an infectious illness of the liver caused by the hepatitis B virus (HBV) that affects apes, including humans. It was originally known as "serum hepatitis" (Barker LF et al., 1996). Many people have no symptoms during the initial infection. Some develop an acute illness with vomiting, yellow skin, dark urine and abdominal pain. Often these symptoms last a few weeks, and rarely result in death. It may take 30 to 180 days for symptoms to begin. Less than $10 \%$ of those infected develop chronic hepatitis B in those with chronic disease cirrhosis and liver cancer may eventually develop. (Sleisenger et al., 2006). The virus is transmitted by exposure to infectious blood or body fluids. (Barker LF et al., 1996). Infection around the time of birth is the most frequent way hepatitis $B$ is acquired in areas of the world where the disease is common. In areas where the disease is rare intravenous drug use and sex are the most frequent routes of infection. Other risk factors include working in a health care setting, blood transfusions, dialysis, sharing razors or toothbrushes with an infected person, travel in countries where the infection rate is high, and living in an institution. (Sleisenger 2006).

Tattooing and acupuncture led to a significant number of cases in the 1980s; however, this has become less common with improved sterility. (Hoboken, 2013) The hepatitis B viruses cannot be spread by holding hands, sharing eating utensils or drinking glasses, kissing, hugging, coughing, sneezing, or breastfeeding. Hepatitis B is an infectious illness caused by hepatitis B virus (HBV) (Engy, 2011) is a common infection of liver in which the liver cells (i.e. hepatocytes) are inflamed. It can be induced by both infectious and non-infectious agents. The former includes a variety of different viruses such as hepatitis A, B, C, D and E. The later includes an over active immune system, use of drugs, alcoholism, chemicals and environmental toxins [2]. 
The infection is caused by Hepatitis B Virus (HBV), an enveloped virus containing a partial or incomplete double-stranded circular DNA genome. It belongs to the family hepadnaviridae. It is $42 \mathrm{~nm}$ long and composed of $27 \mathrm{~nm}$ nucleocapsid core surrounded by an outer lipoprotein coat containing the Hepatitis B surface antigen (HBsAg). The virus interferes with the liver function while replicating in the cytoplasm of hepatocytes [3]. HBV is present in body fluids of the infected person such as blood, serum, vaginal secretions and in saliva though in low concentrations [4]. Although surrounded by a host cell derived envelope, HBV is remarkably stable (to organic solvents. It is also heat and $\mathrm{pH}$-resistant [5]. Young children who become infected with HBV are most likely to develop chronic infection. About $90 \%$ of infants infected during the first year of life and $30 \%$ to $50 \%$ of children infected between 1 to 4years of age develop chronic infection (Taukan 1990). Viral hepatitis is a systemic disease primarily involving the liver. Most cases of acute viral hepatitis are caused by Hepatitis A Virus, Hepatitis B Virus (HBV) or Hepatitis C virus (HCV). The complex antigen found on the surface of HBV called HBsAg.

The presence of HBsAg in serum or plasma is an indication of active Hepatitis B infection, either acute or chronic. Viral hepatitis is now known to be the most common complication of blood transfusion [6]. The hepatitis agents known to be transmitted through blood products include hepatitis B virus (HBV), hepatitis C virus (HCV), hepatitis D virus (HDV), and hepatitis G virus (HGV) [7] Hitherto, only hepatitis A virus (HAV), and HBV were characterized, and hepatitis not caused by these two agents was then referred to as non-A non-B hepatitis (Choo et al., 1989). Both HBV and HIV share similar mode of transmission and risk factors. HIV-infected people are frequently co-infected with HBV [8]. Hepatitis B virus infection is associated with significant morbidity and mortality in patients with HIV infection [9]. Co-infection of HIV with HBV affects number of patients worldwide (Liang TJ 2009). The HBsAg One Step Hepatitis B Surface Antigen Test Strip (Serum/ Plasma) is a rapid test to qualitatively detect the presence of HBsAg in serum or plasma specimen. The test utilizes a combination of monoclonal and polyclonal antibodies to selectively detect elevated levels of HBsAg in serum or plasma. However, universal vaccination stil1 remains a goal rather than an accomplished fact, and the World Health Organization (WHO) estimates that there are currently 400,000,000 individuals worldwide who arechronical1y infected with HBV, of whom $25 \%$ will die of chronic liver disease or hepatocel1ular carcinoma [10].

In Nigeria, several reports have established the endemic nature of HBV by the presence of HBsAg in different population groups from different parts of the country. Currently there are four recognized modes of transmission of HBV infection namely: mother to child at birth (perinatal); Contact with infected person (horizontal); sexual contact (inter course) and parenteral (blood to blood) exposure to blood or other fluids [4]. Many people infected with hepatitis B virus never develop signs and symptoms. However, in others, it is associated with loss of appetite, nausea and vomiting, weakness and fatigue, abdominal pain, especially around the liver, dark urine, yellowing of skin and the whiteness of eyes (jaundice), joint pain, mild fever, headache, muscle aches, diarrhea and dark coffee colored stools [11]. The original assays for detection of hepatitis B virus infection involve serum or blood tests that detect either viral antigens or antibodies [12]. There are no specific treatments for the acute symptoms of hepatitis B virus infection, but in most cases bed rest, prevention of dehydration, balanced diet and avoidance of alcoholic beverages are recommended [13]. It can be prevented by avoiding contact with infected blood and body fluids, including semen and vaginal secretions of infected individuals [4]. This study therefore, is designed to determine the prevalence and incidence of HBsAg among pregnant women attending antenatal clinic at general hospital, Awka, Anambra State, Nigeria.

\section{Materials and Methods}

All the materials, reagents used in this study were of highest grade and were obtained at the hospital laboratory.

Study Area: The study area is the general Hospital Amaku located in the capital urban city of Awka, Anambra State. However, the town is characterized by low level of environmental sanitation, sometimes improper management of wastes especially in the indigenous core areas characterized by high density and potable water problem.

Study Population: After informed consent was obtained, a total of 200 pregnant women blood samples were collected from these pregnant women attending the Antenatal Clinic, at general hospital, Amaku, Anambra State Eastern, Nigeria. Ethical approval for this study was obtained from the general Hospital ethical committee. Demographic and clinical information of the subjects were obtained by chart abstraction and recorded on a prepared data collection form. The study groups were also stratified by age distribution. Information was collected on the women's age, trimester, and type of family and risk factor histories, parity and contraceptive practices.

\section{Study Sample: Blood Samples}

\section{Study Design}

The study was carried out between March 2017-December 2017. The location of the present study was general Hospital, Amaku, Anambra State, Nigeria; and the participants were also those attending the hospital. We obtained permission to carry out the study from the Management of the Hospital. Subsequently, the objective and procedures of the study were explained to all consecutive adult patients visiting the hospital and consenting individuals recruited into the study. With well-structured questionnaire forms, pertinent demographic data eg, risk factors, types of family, test results, trimester and parity, were obtained 
from the participants. The data collected included age, gender, patient and their spouses' occupation. About $5 \mathrm{ml}$ blood sample was aseptically collected by venipuncture from each participant into sterile plane bottle. The blood samples were left to form clots at room temperature, after which they were centrifuged for 110 minutes at 200 revolutions., per minute (rpm) to separate serum from clot.

Each blood sample was screened using third generation immunoassay-based test strips for qualitative detection of HbsAg serum (relative sensitivity and specificity of $>99 \%$ and $97.0 \%$ respectively with accuracy of $98.5 \%$ ); the test and result interpretations were done according to the test kit manufacturer's instruction. The assay was carried out using Dia Spot HBsAg rapid test strip by Dia Spot Diagnostics, USA and Clinotech HBsAg (Clinotech diagnostics, Richmond, Canada). These serum/plasma test strips are rapid, one step test for the qualitative of Hepatitis B surface Antigen (HBsAg) in serum or plasma.

Data Analysis: The data generated in this study were analyzed at $5 \%$ level of significance by Chi-square test using contingency table. Data was presented using descriptive statistics for we presented the results of this study with descriptive statistics. In addition, we statistical test to establish difference. We used SPSS 13.0 for the analysis.

\section{Results}

Result of the total 200 samples tested for HbsAg, 23 tested positive giving $\mathrm{HbsAg}$ prevalence of $11.5 \%$. In the age group 30 39 years, a total of 72 samples were tested, out of which 11 tested positive, thus, giving the prevalence of $15.3 \%$. In the age group 29 29 years, a total of 125 samples were tested and 11 (8.8\%) tested positive and in the age group 40-49 years, one sample was tested, and the sample tested positive giving a prevalence of $100 \%$ as shown in Table 1. There exists a significant difference $(\mathrm{P}<0.05)$ in the association between age and prevalence of HbsAg. Distribution of HBsAg in relation to parity (No. of pregnancy) is shown in Table 2. $9(20.9 \%)$ of 43 women who were in their $3^{\text {rd }}$ pregnancy and above or who have had more than 3 children had HBsAg, 2 (4.7\%) of 43 women were in their $2^{\text {nd }}$ pregnancy also had HBsAg while 12 (8.3\%) of the 114 women who were in their $1^{\text {st }}$ pregnancy had antibodies to HBsAg. However, there is sufficient difference $(\mathrm{P}<0.05)$ between the number of parity and HBsAg.

Table 1: Distribution of HbsAg by Age.

\begin{tabular}{|c|c|c|}
\hline Age Group (Years) & No (\%) Tested & No (\%) +ve for $\mathbf{H B}_{\mathbf{s}} \mathbf{A}_{\mathbf{g}}$ \\
\hline Less than 20 & $2(1.0)$ & $0(0.0)$ \\
\hline $20-29$ & $125(62.5)$ & $11(8.8)$ \\
\hline $30-39$ & $72(36.0)$ & $11(15.3)$ \\
\hline $40-49$ & $1(0.5)$ & $1(1000.0)$ \\
\hline Total & $200(100.00$ & $23(11.5)$ \\
\hline
\end{tabular}

Table 2: Distribution of HBsAg by Parity (No. of Pregnancy).

\begin{tabular}{|c|c|c|}
\hline Parity & No (\%) Tested & No (\%) +ve for HBsAg \\
\hline $1^{\text {st }}$ Pregnancy & $114(57.0)$ & $12(8.3)$ \\
\hline $2^{\text {nd }}$ Pregnancy & $43(21.3)$ & $2(4.7)$ \\
\hline $3^{\text {rd }}$ and above & $43(21.5)$ & $9(20.9)$ \\
\hline Total & $200(100.00)$ & $23(11.5)$ \\
\hline
\end{tabular}

Table 3 shows the distribution of HBsAg in relation to trimester (a period of three months, especially one of the three threemonth periods into which human pregnancy is divided for media purposes) as at the time of this study. This revealed that women in their $3^{\text {rd }}$ trimester of their pregnancy had the highest prevalence of HBsAg (104), with 14 (13.5\%) having HBsAg followed by women in their $2^{\text {nd }}$ trimester (81) with 8 (9.9\%) having HBsAg while women in their first trimester of their pregnancy, (15) with 1 (6.7\%) having HBsAg. Statistical analysis showed no significant difference $(\mathrm{P}>0.05)$ between Prevalence of HBsAg and trimester.

Table 3: Distribution of HBsAg by Trimester (Period of 3 ThreeMonths of Pregnancy).

\begin{tabular}{|c|c|c|}
\hline Trimester & No (\%) Tested & No (\%) +ve for HBsAg \\
\hline $\begin{array}{c}\text { First trimester }\left(1^{\text {st }}\right. \\
3 \text { month })\end{array}$ & $15(7.5)$ & $1(6.7)$ \\
\hline $\begin{array}{c}\text { Second trimester } \\
\left(2^{\text {nd }}-3 \text { month }\right)\end{array}$ & $81(40.5)$ & $8(9.7)$ \\
\hline $\begin{array}{c}\text { Third trimester }\left(3^{\text {rd }}\right. \\
\text { - month }\end{array}$ & $104(52.0)$ & $14(13.5)$ \\
\hline Total & $200(100.00$ & $23(11.5$ \\
\hline
\end{tabular}

Table 4 shows the distribution of HBsAg in relation to type of family. This revealed that out of the 6 single pregnant women tested, none had HBsAg. Out of the 178 women in monogamous family, $21(11.8 \%)$ tested positive to HBsAg while 16 women in polygamous family were tested and $2(12.5 \%)$ were positive to HBsAg. Statistically, there is no significant difference between the type of family and prevalence of HBsAg.

Table 4: Distribution of HBsAg by the Type of Family.

\begin{tabular}{|c|c|c|}
\hline Type of Family & No (\%) Tested & No (\%) +ve for HBsAg \\
\hline Single & $6(3.0)$ & $1(6.7)$ \\
\hline Monogamy & $178(89.0)$ & $8(9.9)$ \\
\hline Polygamy & $16(8.0)$ & $14(13.5)$ \\
\hline Total & $200(100.00$ & $23(11.5$ \\
\hline
\end{tabular}

Table 5 shows distribution of HBsAg in relation to other associated risk factors. The results showed that women who had previous history of blood transfusion had the highest prevalence of $57.0 \%$ while those who had no history of blood transfusion have a prevalence of $8.1 \%$. The frequency of HBsAg carriers did not vary significantly with scarification/tribal marks/tattooing/incisions, 
the use of condoms and contraceptives, history of previous surgical operation, and female circumcision $(\mathrm{P}>0.05)$. However, the frequency of HBsAg carriers vary significantly with previous history of transfusion $(\mathrm{P}<0.05)$.

Table 5: Distribution of HBsAg in Relation to Associated Risk Factors.

\begin{tabular}{|c|c|c|}
\hline Risk Factors & No (\%) Tested & No (\%) + ve for HBsAg \\
\hline \multicolumn{3}{|c|}{ History of blood transfusion } \\
\hline Yes & $14(7.0)$ & $8(57.0)$ \\
\hline No & $186(93.6)$ & $15(8.1)$ \\
\hline Total & $200(100.00$ & $23(11.5)$ \\
\hline \multicolumn{3}{|c|}{ Use of condoms and contraceptives } \\
\hline Yes & $22(11.0)$ & $2(9.0)$ \\
\hline No & $178(89.0)$ & $21(11.8)$ \\
\hline Total & $200(100.00$ & $23(11.5)$ \\
\hline \multicolumn{3}{|c|}{ Female circumcision } \\
\hline Yes & $20(10.0)$ & $2(10.0)$ \\
\hline No & $180(90.0)$ & $21(11.7)$ \\
\hline Total & $200(100.00$ & $23(11.5)$ \\
\hline \multicolumn{3}{|c|}{ Tribal mark } \\
\hline Yes & $37(18.5)$ & $4(10.8)$ \\
\hline No & $163(81.5)$ & $19(11.7)$ \\
\hline Total & $200(100.00$ & $23(11.5)$ \\
\hline \multicolumn{3}{|c|}{ History of previous surgical operation } \\
\hline Yes & $20(10.0)$ & $2(10.0)$ \\
\hline No & $180(90.0)$ & $21(11.7)$ \\
\hline Total & $200(100.0)$ & 23 (11.5) \\
\hline
\end{tabular}

\section{Discussion}

The overall prevalence of HBsAg in pregnant women attending antenatal clinic at Ekwulobia General Hospital, Anambra State was $11.5 \%$. The distribution of HBsAg by age shows that women in the age group 40-49years have the highest prevalence of $100 \%$; (1994) reported that age is a co-factor for disease susceptibility and progression, statistical analysis showed no significant difference. The classification of high endemicity from HBV infection base on age distribution has been defined as HBsAg greater $7 \%$ in an adult population (Uneke et al, 2005), (Kiire, 1996), Jombo et al, (2005), Harry et al, (1994), (Euler, et al., 2003). HBsAg was found in $1.7 \%$ of pregnant women in Brazil (Bertolini, et al., 2006), (Obi, et al., 2006), (Elsheikh, et al., 2007). (AI Awaidy, et al., 2006). (Denis, et al., 2004). (Stroffolini et al., 2003).
Analysis of the prevalence of HBV in relation to the type of family revealed a higher prevalence rate among women who are in polygamous families. This may be due to a high of individuals in the family and since most HBV infections are subclinical, infection a member of the family predisposes others to the infection. Statistically, there is no significant difference between the type of family and prevalence of HBsAg among the pregnant women. Higher prevalence among the subjects from polygamous families concurs with the finding of Adoga et at. (2009) among prison inmates in Nasarawa State, Nigeria.

Higher household contacts and sharing of sharp objects such as razor blades for finger-nail cutting with the carriers might account for the higher prevalence found among the subjects from polygamous family. On the other hand, the prevalence of $11.5 \%$ is lower than $16.0 \%$ and $36.0 \%$ prevalence reported by Bada et al. (1996) among ante-natal clinic patients and patients of sexually transmitted diseases respectively.

However, in relation to other risk factors, history of previous blood transfusion accounted for a high proportion of HBsAg infection. This may be due to improper screening of blood and blood products before transfusion. It has been previously reported that human immunodeficiency virus (HIV), hepatitis B virus (HBV) and hepatitis $\mathrm{C}$ virus (HCV) have similar routes of transmission namely through blood and blood products, intravenous drug abuse unsafe injections and sexual activity, shared needle, other body fluids such as semen, virginal fluid and breast milk; intravenous drug abuse, from mother to child, needle stick, injury, ear piercing, tattooing and other barbers razors etc. (Agbede et al., 2007; Olokoba et a1., 2008, (Ezegbudo et al., 2004), (Ugwuja and Ugwu, 2010), (Hollinger and Liang, 2001). (Ugwuja and Ugwu, 2010).

This observation was similar to an earlier-report in Anyigba, Dekina local government area of Kogi State in which pregnant women with history of blood transfusion had significantly higher HBsAg prevalence compared to those without such history (Sule et al., 2007) and Ugwuja and Ugwu (2010), who reported that the major routes of HBV transmission in the population used in their study were unsafe injection, tribal marks/circumcision/ scarification and blood/blood products transfusions. Percutaneous exposures to infected blood and blood products were reported to be the major route of transmission of HCV. Cultural practices such as tattooing, ear piercing, circumcision, face marking (tribal marks) are widely practiced in underdeveloped countries including Nigeria (Odaibo et al., 2003). A similar observation was also made by Motta-Castro et al. (2003) among Afro-descendant community in Brazil [14-17].

However, reported no association of blood transfusion with HBV infection among pregnant women of Ethiopia. In Nigeria, studies on the prevalence of HBsAg among blood donors have been 
documented. Opaleye et al. (2010) reported a prevalence rate of $5.4 \%$ among blood donors in Benin City, Nigeria, concurred. These showed that transfusion of HBV-infected blood was possible in Nigeria. (Gambarin, 2007). World Health Organization (WHO) and Center for Disease Control and Prevention (CDC) advise that HbsAg should be examined in all pregnant women and that infants born to HbsAg-positive mothers should receive hepatitis B vaccine and 0.5 mL HBIG within 12 hours of birth. This offer has begun to be applied widely all around the world. In addition, viral hepatitis preventive board (VHPB) suggests routine screening of pregnant women for HbsAg; if one is found positive, active and passive prophylaxis, and vaccination of the newborn to prevent the perinatally transmission of HBV (Van Damme, 1998) are recommended.

\section{Conclusion and Recommendation}

This study has further provided information on the prevalence of HbsAg infection among pregnant women in Ekwulobia, Anambra State, Nigeria. General surveillance, mass Immunization and public health education to stop the spread of the infection on campus and indeed the whole society is advocated. Free screening and immunization of all pregnant women and their infants should be incorporated in the antenatal and postnatal programmes in hospital to prevent postnatal infection of the infants by the infected mothers.

\section{References}

1. Zukerman AJ (1996) Hepatitis Viruses. In Baron S, et al. Baron's Medical Microbiology ( $4^{\text {th }}$ edn). University of Texas Medical Branch 45(3): 982985.

2. Deinstag DL, Hollinger M, Stephen MD (1995) Epidemiology of Hepatitis B in Europe and Worldwide. Transfuse Medical 10: 185-180.

3. Seeger B, Mason AM (2000) Viral Hepatitis In "Marents and molimand, A.A.F. (eds), Tropical Geographical Medicines 32(2): 572-576.

4. Lindsley TK, Skoutelis A, Bassaris H (1990) Control of Hepatitis B Virus Infection in Third World Countries. Journal of Transfies Medical Review 43(3): 187-190.
5. Holling DM, Gogos AC, Fouka KP (1995) Prevalence of Hssepatitis B and C Viral Infections in the General Population and Selected groups in South Western Greece. Journal of Infectious Diseases 18: 551-557.

6. Stevens CE, Taylor PE, Pindyck J (1990) Epidemiology of hepatitis C virus: a preliminary study of volunteer blood donors. Journal of the American Medical Association 263(1): 49-53.

7. Dao B, Nacro B, Dahourou H (2001) HIV infection and HBV co-infection: survey of prevalence in pregnant women in Burkina Faso. Revenue Medicale de Bruxelles 22(2): 83-86.

8. Ezegbudo CN, Agbonlahor DE, Nwobu GO, Igwe CU, Agba MI, et al. (2004) Thesero prevalence of hepatitis B surface antigen and human immunodeficiency virus among pregnant women in Anambra State, Nigeria. Department of Internal Medicine Shiraz E-Medical Journal 5(2): $1-8$

9. Thio CL, Seaberg EC, Skolasky R (2002) HBV and the risk for liverrelated mortality in the multicenter cohort study. Lancet 360(9349): 1921-1926.

10. Seeger C, Knipe DM, Howley P, Zoulim f, Mason WF (2007) Hepadnaviruses. In Field Virology, ( $5^{\text {th }}$ edn) 60: 2978-3029.

11. Stewart FS, Beswick T (2005) External Lamivudine Retreatment for Chronic Hepatitis B: maintenance of viral Suppression after Discontinuation of Therapy. Hepatology 30: 1082-1087.

12. Ryan S, Ray M (2004) Atlas of Clinical Haematology 60: 326-327.

13. Savel AM, Andelman B (2005) Strategy for the Control of Hepatitis B Viral Infection in the Middle East and North Africa Vaccine 8: 5117-5128.

14. Awole M, Gebre-Selassie S (2005) Seroprevalence of HbsAg and its risk factors among pregnant women in Jimma, Southwest Ethiopia. Ethiopia Journal of Health Development 19(1): 45-50.

15. Adhool, Karim (1991) Transmission of serum hepatisis. The New England Journal of Medicine 285(4): 185-189.

16. Dienstag JL (1981) Hepatitis B as an immune complex disease. Seminars in Liver Diseases 1(1): 45-57.

17. Engy, Yousry, Elsayed, Ashor (2011) Overview on Heptitis B virus. Nature and Science 9(3): 31-36.

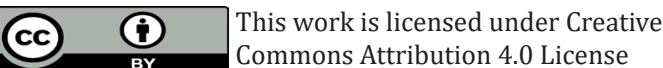

To Submit Your Article Click Here:

Submit Article

DOI: 10.32474/IPDOAJ.2018.02.000129

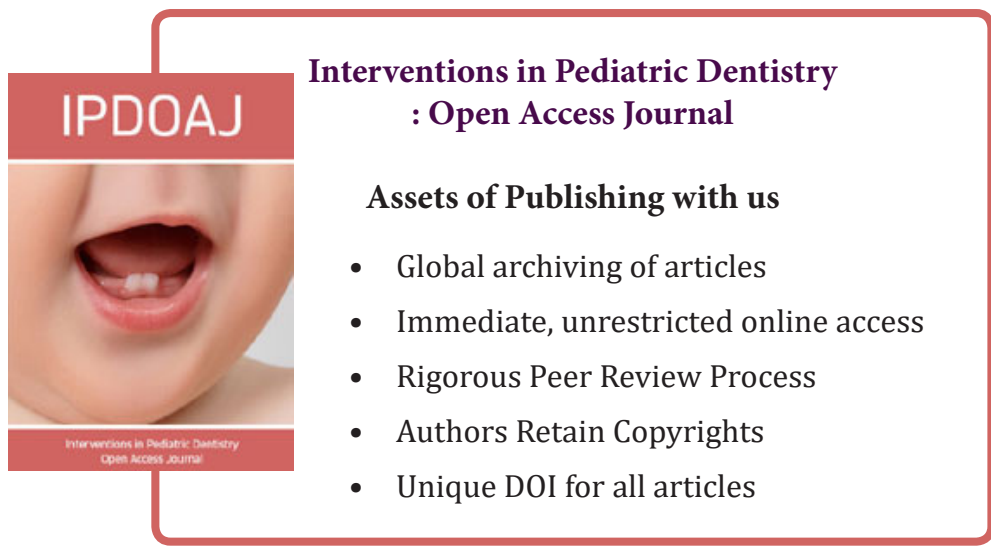

